\title{
PÓS-MODERNIDADE, CIÊNCIA JURÍDICA E ENSINO: POSSÍVEIS CONTRIBUIÇÕES DA TEORIA CRÍTICA NO CENÁRIO BRASILEIRO
}

\author{
POSTMODERNITY, LEGAL SCIENCE AND TEACHING: \\ CONTRIBUTIONS POSSIBLE OF THE CRITICAL THEORY IN THE BRAZILIAN CONTEXT
}

RESUMO: O objetivo desse estudo é discutir a inserção da Ciência Jurídica e do ensino do Direito na pós-modernidade, bem como examinar possíveis contribuições da Teoria Crítica, em Adorno e Horkheimer, para o desenvolvimento da construção do saber e prática pedagógica no Direito. Utilizase de metodologia qualitativa, contando com técnica de pesquisa bibliográfica. Infere-se, da pesquisa realizada, que a Ciência Jurídica na pós-modernidade é líquida, encontra-se em processo de constante modificação, e, o ensino do Direito precisa acompanhar tal dinâmica, o que exige formas de ensino e aprendizagem que não correspondam a uma educação bancária, mas sim emancipatória. Nesse contexto, a Teoria Crítica pode contribuir para a construção do conhecimento e aperfeiçoamento do ensino do Direito, tornando-os reflexivos e críticos, a partir da interação entre teoria e prática.

PALAVRAS-CHAVES: Ciências Jurídicas. Ensino. Pós-modernidade. Teoria

ABSTRACT: The objective of this study is to discuss the insertion of Juridical Science and the teaching of Law in postmodernity, as well as to examine possible contributions of the Critical Theory, in Adorno and Horkheimer, to the development of pedagogical knowledge and practice in Law. It uses a qualitative methodology, counting on a bibliographical research technique. It is inferred from the research carried out that Legal Science in postmodernity is liquid, is in a process of constant modification, and the teaching of Law must accompany such dynamics, which requires forms of teaching and learning that do not correspond to a banking education, but emancipatory. In this context, Critical Theory can contribute to the construction of knowledge and improvement of Law teaching, making them reflexive and critical, based on the interaction between theory and practice.

KEYWORDS:. Legal science. Teaching. Postmodernity. Critical Theory.

1 Mestrando pelo Programa de Pós-graduação em Direito da Universidade Federal do Ceará. Bolsista do CNPQ. Especialista em Direito e Processo Eleitoral pela Universidade Candido Mendes - RJ. 


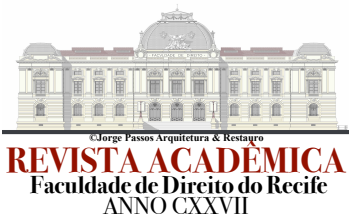

\section{INTRODUÇÃO}

O presente texto disserta sobre Ciência Jurídica na pós-modernidade e o ensino do Direito no Brasil, construindo discussão teórica que permite maior familiaridade com o tema e seus desafios. Igualmente, examina uma potencial contribuição da Teoria Crítica da Escola de Frankfurt, com as ideias de Max Horkheimer e Theodor Adorno, para o desenvolvimento da Ciência e ensino do Direito no cenário brasileiro.

A problemática que impulsiona este estudo gira em torno da seguinte indagação: diante da pós-modernidade, a Teoria Crítica - resultado dos estudos em Filosofia Social desenvolvidos por Horkheimer e Adorno na Escola de Frankfurt - pode contribuir para o desenvolvimento da Ciência e ensino do Direito no Brasil?

Justifica-se a importância destes escritos com fulcro na necessidade de se debater sobre (1) como a Ciência Jurídica é construída na pós-modernidade e (2) de que forma o ensino do Direito deve ser maximizado, ambos a partir da interação entre teoria e prática, para se tornarem reflexivos e esclarecedores.

O objetivo precípuo é analisar a Ciência Jurídica pós-moderna e o ensino do Direito, compreendendo suas essências, e, verificando a existência de possíveis influências e contribuições positivas da Teoria Crítica para o fortalecimento da construção do saber e formação de capital humano na área do Direito.

O método de abordagem é puramente qualitativo, preocupado em conhecer substancialmente a ciência jurídica, o ensino e as contribuições da Teoria Crítica. Natureza básica de pesquisa, almejando a criação de novos conhecimentos e desenvolvimento da ciência neste segmento. Caráter exploratório, tornando o tema mais explícito e construindo hipóteses. Conta com técnica de pesquisa bibliográfica.

Infere-se, da investigação realizada, que a Teoria Crítica pode influenciar e contribuir positivamente a Ciência Jurídica e o ensino do Direito, tornando-os mais próximos da realidade social experimentada de fato, ainda os caracterizando como fenômenos emancipatórios e reflexivos.

O texto está estruturado em três tópicos. O primeiro aborda a crise da ciência moderna, o conceito de pós-modernidade e o processo de construção do conhecimento neste 


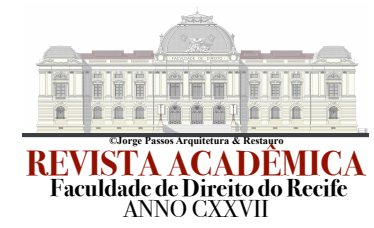

novo tempo. O segundo discorre sobre o ensino do Direito e seus desafios na pósmodernidade. E, por fim, o terceiro tópico trata da Teoria Crítica e suas contribuições para a ciência jurídica e o ensino do Direito.

\section{CIÊNCIA JURÍDICA PÓS-MODERNA}

A crise da modernidade ou crise de relatos já fora prevista por Nietzsche (2006), quando em sua obra $A$ gaia ciência elogia o ceticismo e despreza tudo aquilo que não permite uma experiência ao indivíduo. Para Nietzsche (2006), a veracidade pressupõe uma experiência na descoberta daquilo que as coisas realmente são e o homem racional apesar de querer "dar a entender que o mundo é verdadeiramente feito como lhes aparece" (NIETZSCHE, 2006, p. 79) falha, pois, nesse cenário, não há espaço para a dúvida.

Jean-François Lyotard (1988) explica que a pós-modernidade está diretamente ligada ao fim da ideia de verdade absoluta e universal, o referido autor segue Nietzsche (2006) na conformação da existência de um perspectivismo: a abertura a múltiplas concepções de verdade.

Lyotard (1988, p. xvi) assegura então que é “"pós-moderna', a incredulidade em relação aos metarrelatos. E, sem dúvida um efeito do progresso das ciências; mas este progresso, por sua vez, a supõe". Diante do abandono dos metadiscursos é perceptível a existência de várias categorias de enunciados que possuem sua propriedade e utilização determinadas por um conjunto de regras, os chamados jogos de linguagem (LYOTARD, 1988).

Em relação aos jogos de linguagem é possível pontuar que (1) as regras não são legítimas por si mesmas; (2) ante a ausência de regras, o jogo de linguagem - com inúmeros enunciados - inexiste; e (3) todo enunciado significa um movimento, uma inovação, ainda que seja realizado sem fins científicos precipuamente (LYOTARD, 1988). Pode-se afirmar que na pós-modernidade coexistem diversas perspectivas, diversos enunciados, que por sua vez são o próprio conhecimento, e, que dependem de regras para a sua legitimação. 


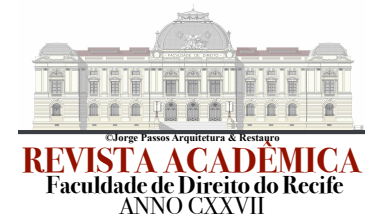

Na pós-modernidade o saber está configurado pela dúvida, pela incerteza, pela desconstrução, pelas perspectivas, pela falta de confiabilidade, pela inexistência de verdades absolutas e universais. A construção do conhecimento neste tempo pós-industrial se dá pela “experiência da experiência”, pela vivência de um problema (KARASEK, 2010). Seguindo este pensamento é possível indicar que a aplicabilidade da Ciência jurídica na pósmodernidade deve se fundar na afirmação existencial de muitas perspectivas, que podem cada uma a sua maneira e por seus próprios métodos - levarem ao avanço científico do Direito.

Para Lyotard (1988) a pós-modernidade tem relação com a epistemologia, a teoria do conhecimento, assim, todos os enunciados dentro do jogo de linguagem detêm certa parcela de veracidade. A ciência passa a produzir perspectivas, concepções, e o contrário de uma verdade não é, de fato, um erro, mas uma outra grande verdade. Nesse contexto, nenhuma concepção é mais importante que a outra, isso deve ser assimilado inclusive na Ciência jurídica. Há então um eterno debate, um eterno processo de construção do conhecimento a partir do dissenso, da contradição. Nietzsche (1998, p. 109) reforça que a diversidade de perspectivas deve ser tomada como algo positivo, de "modo a saber utilizar em prol do conhecimento a diversidade de perspectivas e interpretações afetivas".

A pós-modernidade é marcada por uma volatilidade nas estruturas das artes, ciência e literatura, um contínuo processo de transformação das relações sociais que Bauman (2001) define como liquidez, que diretamente acaba por interferir no campo da ciência. Para o autor “os padrões e configurações [da ciência] não são mais "dados", e menos ainda "autoevidentes"; eles são muitos, chocando-se entre si e contradizendo-se em seus comandos conflitantes, de tal forma que todos e cada um foram desprovidos de boa parte de seus poderes" (BAUMAN, 2001, p. 14), é inequívoco afirmar que o conhecimento, enquanto fruto da ciência na pós-modernidade, nasce do conflito, estando tendente a sofrer "numerosas e profundas mudanças" (BAUMAN, 2001, p. 14).

Karl Popper (2011), Thomas Kuhn (2010) e Paul Feyerabend (1997) possuem posicionamentos extremamente relevantes para o paradigma da ciência na pós-modernidade. Popper (2011) é inimigo ferrenho do dogmatismo e do positivismo, defende que o conhecimento resultante do processo científico é falível e está sujeito a retificações no 


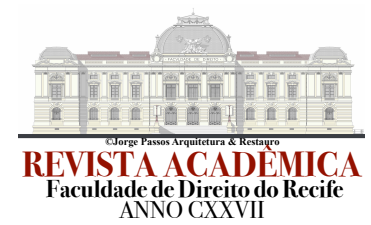

contexto temporal em que se insere, a pesquisa deve ser passível de refutação quanto a suas hipóteses, o que viabiliza a modificação do conhecimento no tempo.

Kuhn (2010) observa que as alterações no conhecimento ocorrem de tempos em tempos e, que estas modificações, impulsionam o progresso científico. Kuhn pontua que os paradigmas são importantes e as revoluções científicas - mutação paradigmática - são permissivos para transformação da forma de se observar o mundo e criar o conhecimento.

Feyerabend (1997), por sua vez, é crítico do estabelecimento de um conjunto exclusivo de regras que dirigem a produção do conhecimento - o chamado anarquismo metodológico. Feyerabend (1997) afirma ser impossível a elaboração de método científico único e imutável, pois, a violação de regras científicas consideras essenciais permite a evolução (FEYERABEND, 2011). "A insistência nessas regras não teria melhorado as coisas, mas detido o progresso" (FEYERABEND, 2011, p.19).

A Ciência jurídica incorre em mudanças paradigmáticas com o advento da pósmodernidade. Tercio Sampaio Ferraz Júnior (2014) explica a existência de problemas na discussão da cientificidade do Direito, primeiro pela própria ambivalência do termo "ciência", segundo pela existência de inúmeros parâmetros para a delimitação da área temática da Ciência jurídica.

Ferraz Júnior (2014) conclui, do panorama histórico, que as teorias jurídicas foram perpassadas por muitas transformações. A Jurisprudência Romana, por exemplo, não possuía a intenção de dar ao Direito um caráter científico, comportamento que permeou os glosadores e os jusnaturalistas modernos. Foi a Escola Histórica alemã que se preocupou em determinar a expressão "Ciência do Direito" (FERRAZ JR, 2014, p. 16) e que "empenhou-se, [...] em dar à investigação do Direito um caráter científico" (FERRAZ JR, 2014, p. 16). O autor explica ainda que "a Escola [...] teve o grande mérito de pôr a si a questão do caráter científico da Ciência do Direito" (FERRAZ JR, 2014, p.31).

No Positivismo, a Ciência jurídica está limitada ao “caráter lógico-formal da construção e da subsunção" (FERRAZ JR, 2014, p. 38). Desta forma, a caracterização do Direito enquanto ciência ocorre pela utilização do método de abstração do fato até o alcance de uma premissa positivada, e, no caminho contrário, a regressão de uma premissa positivada 


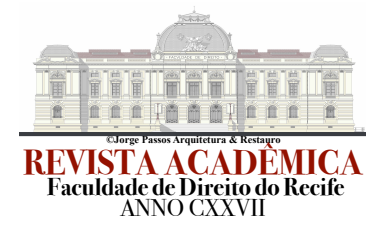

hipotética ao caso concreto. O emprego deste "método" equipararia a Ciência jurídica às ciências naturais, sobrando inexistente qualquer lacuna (FERRAZ JR, 2014).

Com o século $X X$, a Ciência jurídica passa a ser tomada como uma "ciência cultural", envolvendo múltiplas dimensões e teorias, e não mais como o resultado posto de um método pré-determinado dedutivo e indutivo. Tercio Sampaio Ferraz Júnior (2014) explica então que a Ciência jurídica é caracterizada pelo dogmatismo da premissa inicial (a lei posta, tomada como verdade), e posterior problematização na aplicação para resolução de conflitos: a busca pela legitimidade.

Nota-se que a própria ciência jurídica é, com muita certeza, pós-moderna. A pósmodernidade enquanto um momento líquido (BAUMAN, 2001), sujeito a transformações constantes (LYOTARD, 1988), exige que a Ciência do Direito se reinvente a todo momento, em função da infinidade de acontecimentos sociais que não podem ser previstos (BITTAR, 2008), para manter a ordem social por intermédio do Direito.

Ao passo em que o tempo pós-moderno é açodado pela liberdade, a insegurança também o afronta, fazendo com que a ciência enquanto processo de construção do saber, por meio de métodos, esteja inserida por completo dentro da rede de insegurança pós-moderna. Revisitando as escolas que teorizaram sobre Ciência jurídica, é notória a grande transformação que a noção de ciência, e seu respectivo papel, sofre de tempos em tempos.

A Ciência jurídica passa, portanto, a se adaptar às necessidades que lhes são impostas no tempo e no contexto histórico em que está inserida, e assim deve ser. Não pode ser admitido - dentro da pós-modernidade - o desejo da Ciência jurídica em estar acabada e pronta para ser aplicada na busca de uma verdade universal e imutável.

A grande mudança paradigmática na aplicação da Ciência jurídica, em sociedades pós-industriais, reside no desafio de análise da norma e sua aplicabilidade com a utilização de métodos para se chegar o mais próximo possível de uma verdade que seja adequada dentro de determinada perspectiva, não sendo imposto um resultado exclusivamente verdadeiro e irrefutável.

A Ciência jurídica pós-moderna, e é o que se apresenta particularmente adequado, deve abandonar o pensamento socrático-platônico de que só existe uma única interpretação de mundo, e, portanto, uma única verdade. O movimento produtor de conhecimento nas 


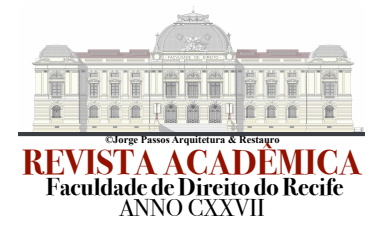

sociedades pós-industriais deve retomar ideias pré-socráticas em relação à constante transformação da realidade, e, diante dessas transformações, não é possível conceber uma ciência do Direito que detenha um único método para a construção do saber e manutenção da ordem social, é necessário delinear a Ciência jurídica como uma forma de interpretar e analisar o mundo que comporte várias concepções verificáveis, sujeitas a uma refutação posterior.

A ciência do Direito tem de ser reflexiva na pós-modernidade, gerando um revisionismo da organização social, sendo cabível a modificação do modus actuandi da criação do conhecimento jurídico, viabilizando assim uma superação constante de perspectivas em relação ao objeto da ciência do Direito, impulsionando um amadurecimento jurídico onde cada enunciado dentro do jogo de verdades possua regras que o legitimem e estejam sujeitos a um falseamento que supere os parâmetros do presente, onde o devir - a constante mutação - gera novas condições de observação da realidade.

O processo de construção do conhecimento científico jurídico, por meio de métodos, tem de estar inserido em um contexto de crise, o mundo é um projeto inacabado e as experiências reais estão em transformação na medida em que o tempo se movimenta e são essas crises, essas lineares transfigurações paradigmáticas, que oferecem revoluções científicas implementadoras de novas figuras axiológicas que permitem um progresso jurídico, como, por exemplo, a conciliação, a pluralidade jurídica, a arbitragem, entre outras práticas (WOLKMER, 2001) que auxiliam o controle social pelo Direito.

Portanto, é assertivo que a Ciência jurídica na pós-modernidade não pode cair na "ingenuidade moderna" de que um método cartesiano é bastante suficiente para o alcance de verdades/respostas definitivas, determinando a veracidade à exaustão de uma imensidão de acontecimentos aos quais a sociedade líquida está exposta.

É do dissenso, da crise, da contradição, da dúvida, da desconstrução e da verdade falseável que nasce o perspectivismo de enunciados jurídicos capazes de propulsar o progresso científico. A Ciência jurídica precisa aceitar continuamente, no contexto pósmoderno, a crítica, a incitação de revisão, o reexaminar de suas práticas, valores, paradigmas e métodos.

\section{ENSINO DO DIREITO NA PÓS-MODERNIDADE BRASILEIRA}




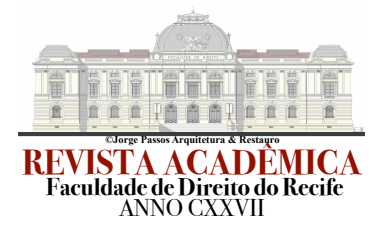

Em 1990, o Brasil possuía 186 cursos de Direito estruturados em uma base curricular datada de 1973. O modelo de ensino deste tempo causou a produção de uma ideologia de insatisfação e descrédito em referência à formação dos profissionais do Direito (MARTINEZ, 2009).

A formação saturada e engessada, já em 1990, impulsionava a não integração dos bacharéis em Direito no mercado de trabalho. Não havia elaboração de competência profissional no sentido de alcançar a resolução de conflitos, o modelo curricular antigo não viabilizava a formação de profissionais aptos a enfrentarem a realidade fora do meio "dito" acadêmico.

A ideia é de que o ensino do Direito brasileiro padece de crise, mas a grande verdade é que as próprias estruturas democráticas, políticas, econômicas e sociais brasileiras atravessam um tempo de crise e reconstrução de suas funções no país. É uma consequência da própria pós-modernidade a transformação de papéis e funções das instituições imersas em um contexto líquido (BAUMAN, 2001), cenário inconstante e passível de alterações a todo momento.

Ligado à crise geral, o próprio Direito entra em crise. Vicente Barreto $(1979, \mathrm{p} .81)$ explica que "não se ensina Direito, mas sim se ensina um conjunto de técnicas de [compreensão e] interpretação legal, que nada tem a ver com o fenômeno Jurídico", sendo insuficiente para a resolução de conflitos práticos e atendimento de demandas sociais.

A crise no Direito não está ligada ao campo jurídico exclusivamente, mas também às possibilidades de construção didática em que o ensino no Brasil está baseado. Fala-se, então, na falência dos meios didáticos de ensino do Direito, não bastando mais a simples exposição de conteúdo, formas insuficientemente capazes de fomentar as discussões e reflexões necessárias para a formação de bons operadores do Direito e criação expressiva da ciência jurídica no Brasil.

A mera exposição de conteúdo e forma permite, apenas, a reprodução de um conhecimento previamente estabelecido, que não incorpora dentro de sua abrangência os fenômenos aos quais a sociedade está sujeita e que o Direito tem de alcançar para promover a organização social. 


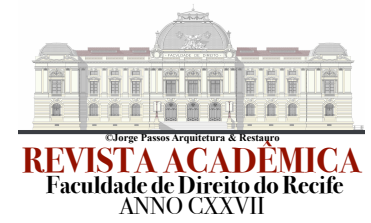

Ensinar o Direito, a partir de uma exegese do ordenamento jurídico positivo, elaborando e promovendo teorias e fórmulas prontas, capazes de alcançar uma resposta para todo e qualquer problema com repercussão jurídica é, na verdade, vedar ao aluno a possibilidade de pensar, refletir e construir uma opinião própria.

O professor passa a ser um expositor ao invés de facilitador de conhecimento, abstratizando o Direito a tal ponto que culmina em um distanciamento da norma e a realidade factual, uma redução puramente positivista do Direito (FARIA, 1987) que não gera conhecimento e muito menos infere bons reflexos na formação do profissional do Direito.

Carvalho (2017) assegura que a crise do ensino do Direito no Brasil está diretamente ligada "à forma pela qual o conhecimento é repassado e assimilado" (p. 6), o estudo do Direito nas instituições de ensino superior em nível de bacharelado passou a ser compreendido no Brasil como a manipulação de documentos normativos, processos, elaboração de petições e participação em audiências. O ensino não satisfaz os anseios que Paulo Freire (1996) prega ao afirmar que educar é substancialmente formar cidadãos. A transmissão de conhecimentos no campo do Direito atualmente tende a ser tratada como algo extremamente mecânico, criando profissionais extremamente "litigadores", indisponíveis a empreenderem buscas por outras formas de resolução de conflitos e pacificação social por intermédio do Direito.

É preciso, a esse ponto, alinhar-se ao pensamento de Paulo Freire (1987) quando trata daquilo que chama de “educação bancária". Para Freire (1987), educação bancária constitui o processo metodológico pelo qual o docente prioriza o processo de memorização e repetição do conteúdo transmitido, que posteriormente será avalizado e extrativizado com base em uma avaliação mensuradora das dimensões do chamado "depósito de conteúdo".

Admitir o ensino do Direito transformado em uma educação bancária acaba por destituir da formação dos bacharéis em Direito a possibilidade de reflexividade em relação aos problemas que chegarão até eles para além dos muros das instituições de ensino superior. É um posicionamento dogmático de ensino jurídico que tende a se tornar um círculo vicioso, inclusive de passível de constatação no Brasil (MARTINEZ, 2009).

A postura dogmática do docente, inserido em uma educação bancária, consolida uma sala de aula infértil do ponto de vista da pós-modernidade, a reflexão é afastada e os grandes 


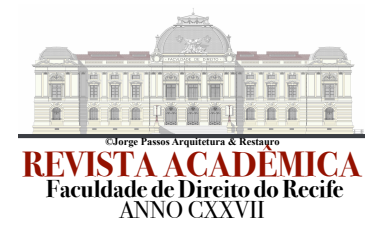

"por quês" acabam findando no âmbito da academia engessada e um tanto quanto ultrapassada. É criada uma relação entre docente, discente e processo de construção do conhecimento, que na realidade não corresponde às necessidades que a sociedade brasileira atual demanda, especialmente quando se observa a perspectiva pluralista e heterogênea da construção social, política e econômica do país.

O grande desafio do ensino do Direito hoje no Brasil, dentro de um contexto temporal pós-moderno, é o abandono do ensino de técnicas e fórmulas legais (BARRETO, 1979) de subsunção do fato à norma, que abstrativiza o Direito, e a adoção de um paradigma de ensino baseado na reflexão, inovação e criação de Ciência jurídica propriamente dita, aqui entendida como a ciência resultante da ação reflexão/inovação.

Assim como a Ciência jurídica se modifica e se supera no decorrer do tempo, como fora visto no tópico anterior, o ensino do Direito, que é fenômeno anterior à própria ciência do Direito, precisa também se reinventar, e, no Brasil é urgente essa necessidade. A reinvenção da educação jurídica, que inevitavelmente deve abrir mão da postura dogmática, aderindo a um processo didático mais reflexivo, deve constituir pauta prioritária das instituições de ensino superior.

O ensino do Direito não pode se fundar em um modelo socrático-platônico moderno, considerando apenas formas e técnicas incapazes de resolverem os conflitos que a comunidade brasileira manifesta rotineiramente.

A formação do profissional do Direito deve viabilizar o processo cognitivo de construção do saber por meio da reflexão e da dialética, que devem estar presentes dentro da prática pedagógica nas universidades e faculdades brasileiras. Não é suficiente saber qual norma se aplica a determinado caso, é importantíssimo observar as várias perspectivas que envolvem os problemas jurídicos.

A distância entre Direito e sociedade constitui um grande problema no campo do ensino, evidente inclusive desde os anos 70 (ALMEIDA, SOUZA e CAMARGO, 2013). O ensino brasileiro atual, no que concerne a seara jurídica, não tem de fato conseguido acompanhar as alterações do mundo pós-moderno, do mundo líquido, não se atualizou na mesma medida em que as estruturas sociais, políticas e econômicas se transformaram. "O ensino do Direito excessivamente legalista e formalista, sem instrumentos de compreensão da 


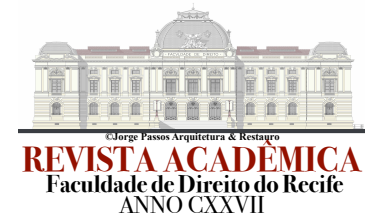

realidade dinâmica da sociedade" (ALMEIDA, SOUZA e CAMARGO, 2013, p. 19) tem aumentado em demasia o abismo entre o Brasil normativo e o Brasil experimentado.

A experiência brasileira precisa ser de uma prática zetética para diminuir o distanciamento entre o Direito e a realidade. Tercio Sampaio Ferraz Jr (2014, p. 21) explica que "zetéticas são, por exemplo, as investigações que têm como objeto o direito no âmbito da Sociologia, da Antropologia, da Psicologia, da História, da Filosofia, da Ciência Política", dessa forma, o ensino acaba por admitir o perspectivismo pós-moderno, maximizando a capacidade de os bacharéis em Direito assimilarem a realidade social e o papel que possuem dentro dela.

Esta abertura à interdisciplinaridade (FERRAZ JR, 2014) e ao perspectivismo pósmoderno (LYOTARD, 1986) é o caminho para a compreensão e manifestação prática do ensino do Direito com base no ensino, pesquisa e extensão, como prescreve a Constituição Federal de 1988.

Conceber o ensino como pós-moderno, passível de inovações e transformações, é permitir que o Direito possa intervir diretamente na realidade social em que o Brasil está inserido. É uma nova forma de vivenciar o ensino superior no curso de Direito, facilitando processos, intervenções e decisões pautadas em uma compreensão ampla da sociedade brasileira.

\footnotetext{
Desde as últimas décadas do século passado, nossa sociedade passa por profundas alterações provocadas principalmente pela revolução das tecnologias de informação e comunicação (TICs), que, além de afetar a vida cotidiana das pessoas, atingiu alguns aspectos fundamentais da própria vida universitária: construção e socialização do conhecimento, formação de profissionais competentes e cidadãos, desenvolvimento da pesquisa, revisão das carreiras profissionais e exigências de responsabilidade social (MASETTO e ZYKOWSKY-TAVARES, 2013, p. 35-36).
}

Com fundamento no pensamento de Masetto e Zykowsky-Tavares (2013), é possível concluir que a revolução no ensino do Direito brasileiro trata-se inequivocamente de sua transformação em um ensino notadamente pós-moderno, contando não só com uma perspectiva legalista, mas abrindo-se a outras perspectivas interdisciplinares, fundamentais para que o Direito acompanhe as necessidades de ordenação da sociedade brasileira, inclusive aquelas demandas cujas soluções não puderam ser previstas pela legislação. 


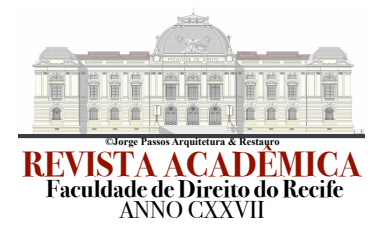

A mudança paradigmática no ensino do Direito, que deve ser essencialmente zetético, constitui o verdadeiro desafio para os docentes e discentes na contemporaneidade brasileira, e implica na permissão para a formação de profissionais de qualidade, bem como, igualmente, no desenvolvimento da Ciência jurídica do país.

O ensino do Direito, de forma zetética e pós-moderna, perfaz o canal para a capacitação dos discentes construírem ao longo de sua formação acadêmica a produção de seus próprios conhecimentos e críticas à realidade legal que se coloca diante deles. É um caminho para a formação de profissionais críticos e para a estimulação do pensamento e manifestação cientifica das opiniões que se formam na academia. Existem repercussões práticas neste sentido, que podem ser significativamente positivas no ensino do Direito.

Nesse cenário, o discente é convidado a pensar e a criar conhecimento jurídico. É possível a prática reflexiva não só em torno da lei pura, mas também de outras questões de ordem prática, como, por exemplo, a admissibilidade de provas ilícitas no processo penal; os limites dos acordos de delação premiada; como aplicar e quais os limites do princípio da insignificância na seara penal; quais as formas de intervenção do Poder Judiciário em questões políticas; o nível de conformação da democracia no Brasil; dentre outras questões que não estão abarcadas somente pelo Direito positivo.

A prática zetética prepara o graduando em Direito para se expressar enquanto formador de opinião, não apenas como um memorizador e repetidor de um conhecimento posto previamente. A atividade reflexiva pode reverberar no trabalho de conclusão de curso TCC, pois, enquanto aluno capacitado e formado para refletir, no contexto do seu TCC, o discente pode externar a sua percepção da relação entre o Direito e a realidade de forma autêntica, evitando inclusive a prática do plágio, gerando conhecimento científico jurídico de qualidade. São inúmeros os reflexos positivos de um ensino do Direito pós-moderno que poderiam ser citados neste estudo.

\section{PODERÁ A TEORIA CRÍTICA CONTRIBUIR PARA A CIÊNCIA E O ENSINO DO DIREITO?}




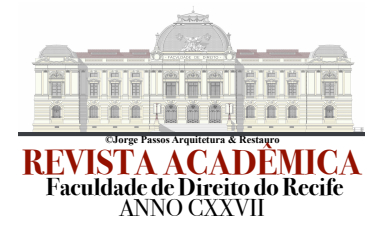

A Escola de Frankfurt nasceu no Instituto de Pesquisas Sociais na Alemanha, cidade de Frankfurt, por decreto do Ministério da Educação em 1923. O primeiro incentivador do Instituto fora Felix J. Weil, responsável por delinear a Escola de Frankfurt enquanto ordem filosófica - reforçada pelas ideias de Grünberg - interessada em outros assuntos, como política e economia. Em 1931 Max Horkheimer chega a direção do Instituto e conforma o seu caráter tal como escola de fillosofia social (ASSOUN, 1991).

Horkheimer tornou explícita a abordagem teórica praticada dentro do Instituto, que buscava a interação entre a teoria e a prática (HORKHEIMER, 1990), restando conhecida como Teoria Crítica.

As duas grandes Guerras Mundiais foram molas propulsoras do pensamento da Escola de Frankfurt, pois, geraram grande desencanto com o legado da racionalidade, da certeza na ciência como resposta para todas as necessidades sociais, desencanto este que Nietzsche já alertara ainda no século XX.

Segundo Max Horkheimer e Theodor Adorno (1985), o nazismo e o fascismo, por exemplo, são resultados de uma grande racionalidade, por mais que a história da humanidade se afaste temporalmente destes regimes totalitários e os imaginem irracionais, Horkheimer e Adorno explicam que o nazismo e o fascismo foram extremamente racionais, científicos, em cada movimento destes regimes havia racionalidade. E é neste contexto que se iniciam os estudos críticos da Escola crítica.

Na Obra A dialética do esclarecimento, Horkheimer e Adorno (1985) consideram que a razão terminou por aprisionar o homem, a chamada razão instrumental, que trouxe evolução tecnológica e científica, mas por sua vez viabilizou uma nova espécie de barbárie: aquela que não leva o ser humano a um patamar de humanização maior. Desta forma "o progresso converte-se em regressão" (ADORNO e HORKHEIMER, 1985, p. 14).

A crítica que os autores fazem à razão instrumental reside no fato dela se orientar por princípios utilitários, inexistindo conflitos entre interesse e moral. Para Adorno e Horkheimer (1985), a razão que permite o homem dominar a natureza finda por elaborar uma dominação repressiva/opressiva, vez que aquele que domina é externo à natureza. Surge assim a razão que restringe a liberdade e autonomia dos dominados, vetando a possibilidade de 


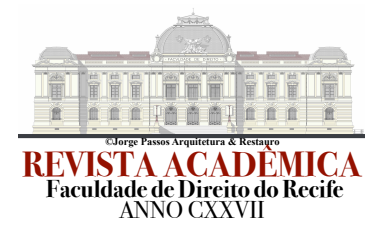

reflexividade crítica em relação à existência do homem e a legitimidade dos valores que são verdadeiramente "impostos".

Tendo como antecedente a Modernidade, Adorno e Horkheimer (1985) pontuam que o movimento histórico não segue desta forma uma evolução positiva, mas antes regride, afundando-se cada vez mais em uma barbárie: a dominação do homem resignado diante da racionalidade posta.

A dominação de um indivíduo acrítico é, para Adorno e Horkheimer (1985), a própria "destruição do esclarecimento" (p.13) que levaria o homem a sair da sua menoridade intelectual, da sua incapacidade de usar o seu entendimento para caminhar na direção daquilo que é melhor para si e para o outro. Como resultado do processo de destruição do esclarecimento, o indivíduo passa a se entregar a padrões de conhecimento e valor de forma acrítica, tendências de fato impostas.

O conceito de esclarecimento não diz respeito a uma época historicamente determinada, mas no entendimento dos autores quer dizer o desencantamento com mundo, desencantamento com tudo aquilo que é posto como absoluto, e, os indivíduos devem utilizar para se libertarem do medo daquilo que é desconhecido. $\mathrm{O}$ esclarecimento deve ser fonte de criticidade.

O esclarecimento não pode ser aceito como mecanismo de dominação do homem sobre o homem, não pode ser aceito como forma através da qual a verdade é criada, com a dissociação entre sujeito e objeto. Se assim o for, na verdade, o esclarecimento é totalitário, desta forma ele se fixa no papel de senhor, pois, busca o controle da totalidade (ADORNO e HORKEIMER, 1985).

No esclarecimento dominador, o conhecimento é imposto e domina ao explicar os acontecimentos sociais, fazendo com que de fato o conhecimento e a ciência sejam um "substrato da dominação", resultado daquilo que é imposto, o próprio esclarecimento. Nesse movimento, o homem acaba se coisificando com relação ao outro e torna-se dominado pelo mecanismo de criação da verdade utilizado na sociedade na qual está inserido. $O$ esclarecimento constitui aquilo que combatera ferrenhamente, a reflexão da natureza alienada no sujeito. 


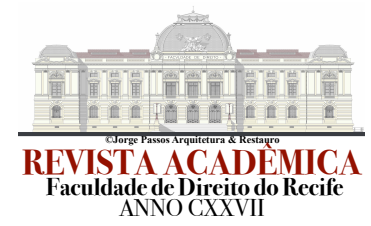

A Teoria Crítica prescreve então que o esclarecimento não deve permitir a dominação, dentro de uma lógica de criação da ciência e imposição de valores, onde aquele que observa os fenômenos sociais está em uma posição externa ao objeto. Em outros termos, a Teoria Crítica estabelece que o esclarecimento/conhecimento não pode funcionar como mecanismo puro de dominação em massa, onde os dominados não têm poder de crítica, mas na contramão, deve viabilizar a atividade crítica reflexiva e emancipadora. "Uma teoria crítica, portanto, é uma teoria reflexiva que dá aos agentes um tipo de conhecimento inerentemente produtor de esclarecimento e emancipação" (GEUSS, 1988, p. 7).

Para Raymond Geuss (1988), a Escola de Frankfurt caracteriza uma teoria crítica acima de tudo pela interação entre teoria e prática, assim como: (1) guia para a atividade humana que esclarece os agentes, (2) emancipatória, libertando o indivíduo de dominação imposta, (c) forma de conhecimento da realidade experimentada e (d) enquanto prática reflexiva.

Diante do exposto, é possível afirmar que a Teoria Crítica pode constituir recurso inestimável à ciência jurídica e ao ensino do Direito, vez que possibilita a discussão e o crescimento no esclarecimento, portanto, o progresso científico e a emancipação dos discentes do curso de Direito.

No que toca a ciência jurídica na pós-modernidade, conforme tratado anteriormente, com as constantes transformações sociais o processo de construção do saber jurídico tem que admitir a crítica, o dissenso, o debate. É nesse meio que a ciência interage com a realidade social vivida. A ciência jurídica abstraída da realidade social e da crítica corresponde a uma percepção tradicionalista de ciência que não é transparente, que conclui impondo o conhecimento como substrato da dominação.

Ciência jurídica sem crítica e dissociada da realidade não é ciência, não corresponde à real função da ciência como meio esclarecedor, apenas reflete o que foi construído de forma isolada em um determinado momento histórico da humanidade (HORKHEIMER, 1975).

O modelo de ciência jurídica tradicional herdada dos gregos, caracterizada pela racionalidade e universalidade, inserida dentro de uma falsa percepção da realidade, deve ser substituído por uma Teoria Crítica do Direito que possibilite a apreensão das situações reais 


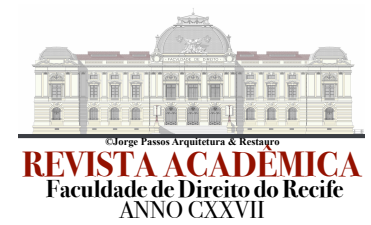

que efetivamente necessitam serem "normadas" pelo direito, dando à ciência jurídica um caráter crítico propriamente dito (COELHO, 2003).

Uma ciência jurídica que não seja crítica cria o que se denomina a esta altura de “alienação jurídica”. Alienação jurídica é o distanciamento entre a norma posta e a realidade social experimentada, o que, consequentemente, acaba resultando também em uma alienação didática material do ensino do Direito.

Horkheimer (1975) afirma que se há uma discrepância entre teoria e prática, com muita categoria há algo errado que envolve ou teoria, ou prática, ou ainda a percepção de ambas. No Brasil, é notório o abismo entre teoria e prática, basta observar as disposições constitucionais sobre direitos fundamentais e a concretização destes direitos, ou ainda, as disposições da Lei de Execução Penal (LEP) e a realidade das varas de execução penal e dos presídios brasileiros.

Nesse cenário, dentro da sala de aula os discentes não são convidados a discutirem e criticarem a própria realidade social em que estão imersos, mas antes são colocados dentro de salas para experimentarem a chamada educação bancária, aprendendo e assimilando o saber jurídico que diz respeito a uma realidade social ideal.

Dessa forma, o ensino jurídico no Brasil precisa adotar metodologias didáticas que estejam colocadas dentro de um aspecto crítico e possibilitem aos discentes a oportunidade de crítica e reflexão sobre o Direito e a realidade, promovendo a emancipação dos discentes.

Portanto, afirma-se categoricamente que a Teoria Crítica tem muito a contribuir positivamente para o desenvolvimento da ciência jurídica e do ensino do Direito no Brasil, dentro de um contexto pós-moderno, aproximando teoria e prática, especialmente por concatenar a ciência jurídica e o ensino como guias para a atuação dos profíssionais do Direito dentro da sociedade, emancipando, gerando conhecimento baseado na realidade social de fato, e, propiciando a prática reflexiva dentro dos cenários em que o Direito e sua ciência são criados, ensinados e aplicados.

\section{CONCLUSÃO}




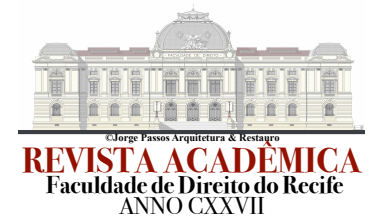

A Ciência jurídica modificou-se ao longo do tempo para acompanhar as transformações que a sociedade mundial sofreu, principalmente em função das transformações tecnológicas e industriais. Zygmunt Bauman, Nietzsche e Lyotard explicam que a sociedade passou a ser líquida e a ciência não detém mais um único método para explicar a realidade, sendo refutada cotidianamente.

A educação jurídica, especialmente no Brasil, é extremamente reducionista e legalista, por assim dizer, dogmática, transformando professor e aluno em instrumentos de um processo de educação bancária, baseada na memorização e reprodução de conhecimento, o que não viabiliza uma prática reflexiva e interdisciplinar da sociedade e seus fenômenos, distanciando o Direito da realidade experimentada pelo país.

Nota-se que o principal desafio do Direito é a modificação na construção da sua ciência e no paradigma da educação jurídica, que devem passar da dogmática para a zetética, possibilitando uma maior compreensão dos fenômenos sociais e acompanhamento das transformações do mundo pós-moderno, formando capital humano capaz de refletir sobre a relação entre norma jurídica e fato social, não apenas isoladamente, mas em uma perspectiva interdisciplinar, real, contextualizada.

A Teoria Crítica, formulada pela Escola de Frankfurt, pode auxiliar a Ciência e o ensino do Direito na medida em que os tornam mais próximos da prática e reflexivos. Diante de uma Ciência do Direito que deve nascer da crítica e do dissenso, e do ensino que precisa ter caráter zetético, os ideais de Adorno e Horkheimer, que delinearam uma teoria crítica, permitem que haja uma interação efetiva entre a teoria e a prática social.

A influência da Teoria Crítica na Ciência jurídica faz com que o esclarecimento, enquanto criação de conhecimento, não seja apenas substrato da dominação, mas de fato espelhe a aproximação entre a Ciência do Direito e a realidade social que deve ser normatizada, tornando os agentes - discentes e operadores do Direito - inseridos na realidade e emancipados à medida que compreendem e participam do processo de relação entre teoria e prática.

Portanto, a Teoria Crítica pode potencialmente outorgar à Ciência jurídica e ao ensino do Direito a característica da reflexividade, tornando-os compartilháveis, criticáveis e 


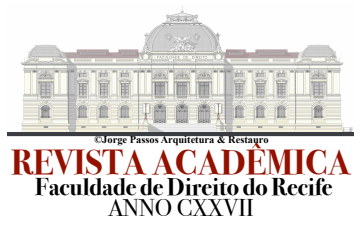

sujeitos ao controle social, aquilo - o conhecimento - que antes era restrito a métodos específicos em determinado lapso histórico-temporal.

\section{REFERÊNCIAS}

ADORNO, Theodor.; HORKHEIMER, Max. Dialética do esclarecimento: fragmentos filosóficos. Tradução: Guido Antônio de Almeida -Rio de Janeiro: Jorge Zahar Ed. 1985.

ALMEIDA, F. de.; SOUZA, André L. D.; CAMARGO, Sarah. Direito e realidade: desafios para o ensino jurídico. In: GHIRARDI, José G.; FEFERBAUM, Marina. (Orgs). Ensino do Direito em debate: reflexões a partir do $1^{\circ}$ seminário ensino jurídico e formação docente. São Paulo: Direito GV, 2013.

ASSOUN, Paul-Laurent. A escola de Frankfurt. Tradução Dr. Helena Cardoso. São Paulo. Editora Ática. 1991.

BARRETO, Vicente. Sete notas sobre o ensino jurídico. In: UNIVERSIDADE DE BRASÍLIA. Encontros da UnB. Ensino Jurídico. Brasília: UnB, 1978 - 1979.

BAUMAN, Zygmunt. Modernidade e ambivalência. Tradução Marcos Penchel. Rio de Janeiro: Jorge Zahar, 1999.

Modernidade líquida. Rio de Janeiro: Jorge Zahar, 2001.

BITTAR, Eduardo C. B. O direito na pós-modernidade. Revista Sequência, 2008. Disponível em: <https://periodicos.ufsc.br/index.php/sequencia/article/download/ 2177-7055.../13642>. Acesso em: 10. jul. 2017.

CARVALHO, N. P. Uma análise do ensino jurídico no Brasil. Disponível em: < $\underline{\text { http:// }}$ www.uni7setembro.edu.br/recursos/imagens/File/direito/ic2/vi_encontro/ Uma analise do ensino juridico no_Brasil.pdf>. Acesso em: 15. jul. 2017.

CHARLE, Christophe.; VERGER, Jacques. História das universidades. São Paulo: UNESP, 1996.

COELHO, Luiz Fernando. Teoria crítica do direito. 3 ed. Belo Horizonte: Del Rey, 2003.

FARIA, José E. A Reforma do Ensino Jurídico. Porto Alegre: Sérgio Antônio Fabris Editor, 1987.

FERRAZ JR, Tercio Sampaio. A ciência do direito. São Paulo: Atlas, 2014. 


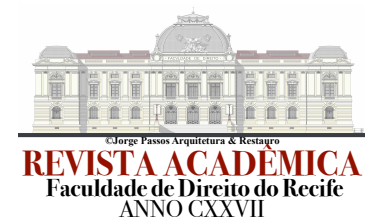

FEYERABEND, Paul. A ciência em uma sociedade livre. São Paulo: UNESP, 2011.

Contra o método. Tradução: Octanny da Motae Leonidas Hegenberg.

Rio de Janeiro: Francisco Alves, 1997.

FREIRE, Paulo. Pedagogia como autonomia: saberes necessários à prática educativa. 30 . ed. São Paulo: Paz e terra, 1996.

. Pedagogia do oprimido. 27. ed. Rio de Janeiro: Paz e terra, 1987.

GEUSS, Raymond. Teoria Crítica: Habermas e escola de Frankfurt. Tradução de Bento Itamar Borges. Campinas: Papirus, 1988.

HORKHEIMER, Max. Teoria crítica: uma documentação. Tradução Hilde Cohn. São Paulo: Perspectiva: Editora da Universidade de São Paulo. 1990.

. Teoria tradicional e teoria crítica. São Paulo: Victor Civita Ed, 1975.

KARASEK, Felipe S. O conceito de pós-modernidade em Lyotard e a possibilidade de influência nitizschiana. Porto Alegre: Famecos PUCRS, 2010.

KUHN S. Thomas. A estrutura das revoluções científicas. Tradução: Beatriz Vianna Boeira e Nelson Boeira. 10. Ed. São Paulo: Perspectiva, 2010.

LYOTARD, Jean-François. O pós-moderno. Rio de Janeiro: José Olympio Editor, 1988.

MARTINEZ, Sérgio Rodrigo. A evolução do ensino jurídico no Brasil. Disponível em: $<$ http://www.egov.ufsc.br/portal/sites/default/files/anexos/29074-29092-1-PB.pdf. $>$. Acesso em: 23. jul. 2017.

MASETTO, Marcos T.; ZUKOWSKY-TAVARES, Cristina. Inovação e universidade. In: GHIRARDI, José G.; FEFERBAUM, Marina. (Orgs). Ensino do Direito em debate: reflexões a partir do $1^{\circ}$ seminário ensino jurídico e formação docente. São Paulo: Direito GV, 2013.

NIETZSCHE, Frederich. A gaia ciência. São Paulo: Escala, 2006.

Genealogia da moral. São Paulo: Cia das artes, 1998.

POPPER, Karl. A lógica da pesquisa científica. São Paulo: Cultrix, 2011.

WOLKMER, Antonio Carlos. Pluralismo jurídico: fundamentos de uma nova cultura no direito. 3. ed. São Paulo: Alfa-Ômega, 2001.

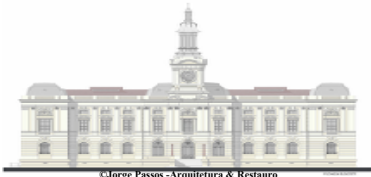

